\title{
Aerosol light absorption in the North Atlantic: trends and seasonal characteristics during the period 1989 to 2003
}

\author{
C. Junker ${ }^{1,2}$, S. G. Jennings ${ }^{2}$, and H. Cachier ${ }^{3}$ \\ ${ }^{1}$ Laboratoire d'Aérologie (URA CNRS 354), Université Paul Sabatier, Toulouse, France \\ ${ }^{2}$ Atmospheric Research Group, Department of Physics, National University, Galway, Ireland \\ ${ }^{3}$ Laboratoire des Sciences du Climat et de l'Environnement, Laboratoire mixte CNRSCEA, av. de la Terrasse, 91198 Gif sur \\ Yvette, France
}

Received: 21 September 2005 - Published in Atmos. Chem. Phys. Discuss.: 19 December 2005

Revised: 16 March 2006 - Accepted: 30 March 2006 - Published: 2 June 2006

\begin{abstract}
Aerosol light attenuation on quartz fibre filters has been measured since February 1989 at the Mace Head Atmospheric Research station near Carna, Co. Galway, Ireland, using an Aethalometer.

The frequency of occurrence of the hourly averaged aerosol absorption data is found to be bimodally distributed. The two modes result from clean marine air and anthropogenically polluted continental air both being advected to the station dependent on the prevailing wind direction. The hourly averages of the marine portion of the aerosol light absorption are found to follow closely a lognormal distribution with a geometric mean of $0.310 \mathrm{Mm}^{-1}$. The hourly averages of continental sector aerosol absorption are neither normally nor lognormally distributed and have an arithmetic mean of $6.36 \mathrm{Mm}^{-1}$, indicating the presence of anthropogenic sources for BC east of the Mace Head station.

The time series of the monthly averaged attenuation coefficient $\sigma_{\text {att }}$ of both marine and continental sector aerosol shows an increase from 1989 to 1997 and a levelling off thereafter.

The monthly maximum of marine sector $\sigma_{\text {att }}$ is found in May. Trend and seasonal characteristics of the clean marine aerosol attenuation coefficients observed at Mace Head appear to be driven by meteorological factors, as indicated by rainfall data and by trends in the North Atlantic Oscillation (NAO) indices. The observed increasing trends of the continental sector $\sigma_{\text {att }}$ from 1989 up to 1997 are possibly related to changes in BC emissions over Ireland, calculated from UNSTAT (2002) fuel consumption data.
\end{abstract}

Correspondence to: C. Junker

(junker@ncuen.ncu.edu.tw)

\section{Introduction}

The effects of anthropogenic particulate emissions in the atmosphere are well documented in the literature (Turco, 1997; Seinfeld and Pandis 1998; Houghton et al., 2001; Johnson et al., 2004), but the magnitude and even the sign of the effect are still uncertain. The ability of aerosols to absorb and scatter incident radiation are key properties which influence the magnitude and sign of their effects.

While light-scattering aerosol generally contributes to tropospheric cooling, light-absorbing aerosol causes atmospheric warming through the direct aerosol effect, i.e. the transmission of the absorbed heat to the atmosphere (Haywood and Ramaswamy, 1998; Jacobson, 2001), the semi direct effect, i.e. the dissipation of clouds through their warming due to the heat generated by absorbing aerosol within the cloud (Hansen et al., 1997; Ackerman et al., 2000; Johnson et al., 2004), and by reducing the albedo of snow and ice surfaces (Hansen and Nazarenko, 2004). Most aerosols are transparent (e.g. sulphates) and are thus scatterers of radiation. Absorbing aerosol consists predominantly of black carbon aerosol (BC) which results from incomplete combustion of carbonaceous fuels.

$\mathrm{BC}$ particles, either externally or internally mixed with hygroscopic aerosol or particulate organic carbon (OC), can also serve as cloud condensation nuclei. Besides, BC can act as a catalyst for various atmospheric heterogeneous chemical reactions. Thus, $\mathrm{BC}$ is an important constituent of the atmosphere that affects the atmospheric radiation balance through both direct and indirect effects and through atmospheric chemical processes.

Published by Copernicus GmbH on behalf of the European Geosciences Union. 
Nomenclature

\begin{tabular}{ll}
\hline ATN & negative logarithmic attenuation \\
BC & black carbon \\
$C_{M}$ & mass concentration of particles suspended in a medium $\left[\mathrm{g} / \mathrm{m}^{3}\right]$ \\
$C N n c$ & condensation nuclei number concentration \\
$g m$ & geometric mean \\
$I$ & light intensity \\
$m$ & indicator variable \\
$M_{S}$ & surface mass loading of particles on a filter $\left[\mathrm{g} / \mathrm{m}^{2}\right]$ \\
$\mathrm{NAO}$ & North Atlantic Oscillation \\
OC & organic carbon \\
$p$ & probability \\
$r$ & correlation coefficient \\
$s$ & standard deviation \\
$S$ & seasonal index \\
$t$ & variable representing time \\
$W D$ & wind direction \\
$\alpha$ & intercept in the autoregression equation \\
$\beta$ & slope in the autoregression equation \\
$\varepsilon$ & error term in the autoregression equation \\
$\sigma_{\text {att }}$ & attenuation coefficient, the light attenuation of \\
& a particle laden fibrous filter divided by the sampled \\
& air column thickness [m $\left.{ }^{-1}\right]$ \\
$\sigma_{\text {ATN }}$ & mass attenuation efficiency of BC aerosol suspended \\
& in a fibrous filter matrix $\left[\mathrm{m}^{2} / \mathrm{g}\right]$ \\
\hline &
\end{tabular}

Long-term measurements of background aerosol focusing on $\mathrm{BC}$ have been carried out at remote sites and in marine environments (Jennings et al., 1997; Cooke et al., 1997; Sharma et al., 2004), in alpine and polar regions (Bodhaine, 1995; Wolff and Cachier, 1998; Lavanchy et al., 1999), and in rural areas (Macias et al., 1981; Wolff et al., 1982; Andreae et al., 1984; Pinnick et al., 1993). Additional studies are still necessary to obtain a more complete picture of the global distribution of $\mathrm{BC}$ aerosol in the planetary boundary layer.

While some previous works (Bodhaine et al, 1995; Sharma et al., 2004) report shorter periods (of the order of 5 to 10 years or so) of continuous aerosol absorption measurements in the Arctic, this work represents the first time series of marine aerosol light attenuation spanning more than one decade. Since aerosol absorption is known to be proportional to $\mathrm{BC}$ aerosol mass concentration $\left(C_{M, \mathrm{BC}}\right)$ under particular conditions (Jennings and Pinnick, 1980; Liousse et al, 1993), this work represents an important addition to existing studies of background black carbon aerosol. This knowledge of longterm changes in background $\mathrm{BC}$ aerosol will help to assess the effect of $\mathrm{BC}$ emissions on regional and global climate.

The main objectives of the work are as follows:

(i) to report on the relatively long time series (14 years) of aerosol absorption measurements at Mace Head,

(ii) to carry out a statistical analysis of aerosol absorption data for marine, continental and un-sectored air masses, (iii) to determine trends of aerosol absorption for marine, continental and un-sectored air masses over a 14 year period from February 1989 up to March 2003.

\section{Mace Head Atmospheric Research Station}

The measurements reported in this paper were made at the Mace Head Atmospheric Research Station near Carna, Co. Galway, Ireland. The station is situated on the Atlantic ocean coastline $88 \mathrm{~km}$ west of Galway city (population of 70000 approximately) as shown in Fig. 1. The area surrounding the station consists mainly of cattle pastures including a few single houses all of which are situated downwind of the station. Other economic activity consists of fish farming mainly along the coastline. There is no significant boat traffic near the site, and the main Atlantic shipping routes run more than $150 \mathrm{~km}$ to the west of the station. The transatlantic corridor for air traffic is located about $80 \mathrm{~km}$ to the north. There are no plantations of trees close to the site.

\section{Meteorology and Sectorisation of the measurements}

Air masses arriving at the station are dominated by westerly winds from the Atlantic Ocean. This is illustrated by the wind rose in Fig. 2, which is based on hourly wind speed and wind direction data from February 1989 to March 2003. The marine sector lies between $190^{\circ}$ and $300^{\circ}$, and the continental sector between $45^{\circ}$ and $135^{\circ}$.

Marine sector winds prevail during about half of the time and continental sector winds during about $20 \%$ of the time. The majority of marine sector air masses are not significantly influenced by human activity. These air masses are considered to represent relatively clean air, and are generally suitable for making baseline aerosol measurements. However, pollution events may influence marine sector air occasionally. Back trajectory analysis using the HYSPLIT 4 (Hybrid Single-Particle Lagrangian Integrated Trajectory, version 4) model (Draxler and Hess, 1998) shows that sometimes air originating overland in Ireland, the UK or mainland Europe can be advected in its approach to the site by winds from the marine sector. The 72 hour back trajectory shown in Fig. 3 gives an example of such an event, where air originating in the North sea close to the Netherlands, traversing over central UK was advected to the site by winds from the marine sector, and arriving at Mace Head at 06:00 UTC, 26 August 1999. The hourly averaged aerosol attenuation coefficient was measured to be $8.3 \mathrm{Mm}^{-1}$ at that time, which is much higher than typical clean marine values of order 0.2 $1.0 \mathrm{Mm}^{-1}$. These events can be filtered from the data by means of condensation nuclei number concentration $(\mathrm{CNnc})$ measurements when exclusively clean marine air is required to be analysed.

However, CNnc were not measured during all of the time series of attenuation measurements. Furthermore, in some 


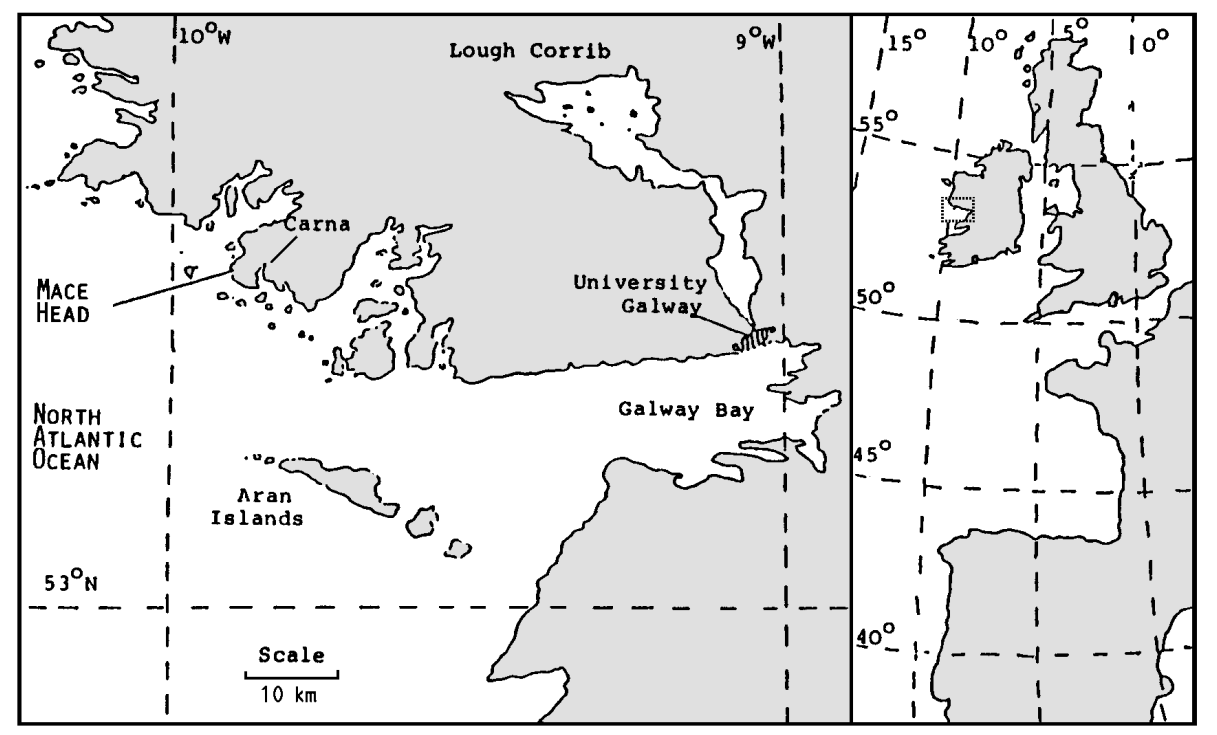

Fig. 1. Location of the Mace Head Atmospheric Research Station on the West coast of Ireland.

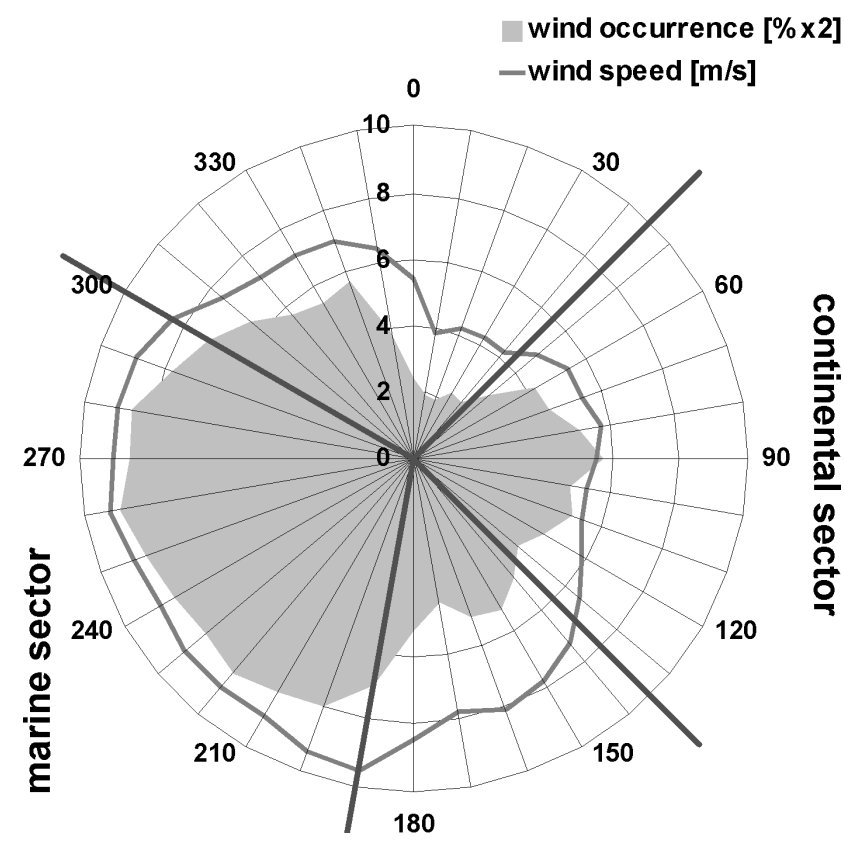

Fig. 2. Wind speed and direction occurrence at Mace Head for the period 2/1989-3/2003. The thick straight lines represent the limits of marine and continental sector.

instances where influence of anthropogenic pollution is indicated by elevated $\sigma_{\text {att }}$, back trajectory analysis does not indicate a continental origin of the particular air mass. It is possible that in those cases, local winds such as sea breezes can cause the mixing of originally clean air with locally polluted air (Simpson, 1994), or that the calculated back trajectories do not always represent the true origin of the airmasses (Stohl, 1998). Thus, even the combined use of local

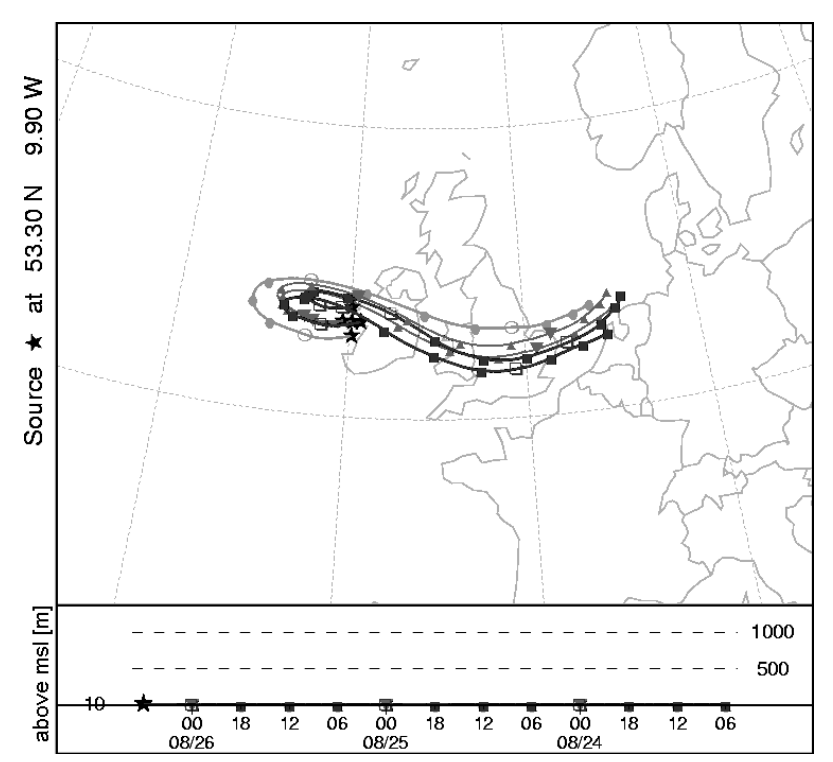

Fig. 3. 72 hour back trajectories ending at 06:00 UTC, 26 August 1999 at Mace Head. The hourly averaged local wind direction was $243^{\circ}$.

wind direction information and back trajectory analysis is not sufficient to filter out anthropogenic pollution events from the time series of marine sector aerosol attenuation. Therefore, polluted airmasses were filtered out from the marine sector $\sigma_{\text {att }}$ time series analysis by excluding hourly averages with $\sigma_{\text {att }}>1.425 \mathrm{Mm}^{-1}$ (BC mass concentration $\left.>75 \mathrm{ng} / \mathrm{m}^{3}\right)$. The threshold value of $\mathrm{BC}$ mass concentration $=75 \mathrm{ng} / \mathrm{m}^{3}$ to indicate the presence of anthropogenically influenced airmasses has been proposed by Cooke et al. (1997) based on a comparative study of aerosol attenuation and CNnc. In their 
analysis, they used a limiting value of $C N n c=700 \mathrm{~cm}^{-3}$ to indicate anthropogenic pollution, (T. C. O'Connor, personal communication).

The suitability of this criterion was confirmed in this work by a statistical analysis on a five year data set of $C N n c$ and $\sigma_{\text {att. }}$ The analysis was based on the fact that $C N n c$ is an indicator of anthropogenic pollution and that the frequency of occurrence of both $C N n c$ and $\sigma_{\text {att }}$ can be approximated by lognormal distributions. The analysis showed that $81 \%$ of the marine sector hourly attenuation coefficients were lower than $1.425 \mathrm{Mm}^{-1}$ when hourly averages with $C N n c>=700 \mathrm{~cm}^{-3}$ were filtered out.

\section{Instrumentation and experimental procedures}

Magee Scientific Aethalometer Models AE-8 and AE-9 with manual filter change have been used for continuous aerosol attenuation measurements at Mace Head since February 1989. The model AE-08 was used up to December 1993, and Model AE-9 is in use up to the present time. The internal functioning of the two models, described below, is identical. The differences between the two models arise from some component upgrades in model AE-9 ( A. D. H. Hansen, personal communication, 2003). The instruments operate by measuring the attenuation of broad band white light through a quartz fibre filter, whilst air is being drawn through the filter (Hansen et al., 1982, 1984). Both instruments operate with manual filter change. Filter changes are performed when the indicated attenuation corresponds to a light intensity through the sampling spot $I_{1}$ of about 0.37 of the intensity through the blank portion of the filter $I_{0}$. A study by Gundel et al. (1984) has shown that for light attenuations $1>I_{1} / I_{0}>0.14$ the negative logarithmic attenuation (ATN), given by

$\mathrm{ATN}=-\ln \left\{I_{1} / I_{0}\right\}$

is proportional to the black carbon surface loading $\left(M_{S, \mathrm{BC}}\left[\mathrm{g} / \mathrm{m}^{2}\right]\right)$ of the filter through the relationship $M_{S, \mathrm{BC}}=\mathrm{ATN} / \sigma_{\mathrm{ATN}}$, where $\sigma_{\mathrm{ATN}}$ is the $\mathrm{BC}$ mass attenuation efficiency. The default value of $\sigma_{\mathrm{ATN}}$ for the white light Aethalometer (up to model AE-10) has been set to $19 \mathrm{~m}^{2} / \mathrm{g}$, based on the results of Gundel et al. (1984) and on laboratory tests comparing white light to monodisperse light absorption (A. D. H. Hansen, personal communication, 2003).

\section{BC mass attenuation efficiency $\sigma_{\mathrm{ATN}}$}

Work by Liousse et al. (1993), Bodhaine (1995), Petzold et al. (1997), Lavanchy et al. (1998) and Sharma et al. (2002) shows that the mass attenuation efficiency of $\mathrm{BC}$ aerosol may be different for different sites, different air masses, aerosol age, degree of mixing etc., leading to uncertainty in the inference of BC mass. For particles deposited onto filters, values of $\sigma_{\mathrm{ATN}}$ ranging from $4 \mathrm{~m}^{2} / \mathrm{g}$ to approximately $25 \mathrm{~m}^{2} / \mathrm{g}$ have been reported. Hence an attempt was made to establish air mass specific BC mass attenuation efficiencies for the Mace Head site by relating the white light attenuation of sector-controlled sampled quartz fibre filters to their BC content. The $\mathrm{BC}$ content of the samples was determined by the thermal method of Cachier et al. (1989) and by the thermooptical method using the SUNSET carbon analyser with a derivation of the DRI thermal protocol described by Chow et al. (1993). The modification of the DRI protocol is primarily that transmission measurements instead of reflection measurements are used for the charring correction. The optical analysis of the quartz fibre filters was performed using an Aethalometer AE-8. The white light attenuation through the sampling spot of the filters from the sector controlled sampling was measured before and after exposure of the filter. The filters were collected for analysis when visual inspection indicated a light to medium grey shade of the sampling spot, corresponding to a range of light attenuation $I_{1} / I_{0}$ values from 0.81 to 0.17 . This is within the range of linear dependence of ATN on $C_{M, \mathrm{BC}}$ and corresponds to a range of ATN values from 0.22 to 1.78 (Eq. 1).

An air mass control system described in detail by Junker (2004) was used to take aerosol samples from exclusively clean marine air and exclusively continental air. The system used $C N n c$ measured by a TSI 7610 particle counter in addition to wind sector control in order to exclude polluted airmasses from marine sector air. Marine sector air was excluded from sampling if the $C N n c$ exceeded $900 \mathrm{~cm}^{-3}$. This value was used instead of $700 \mathrm{~cm}^{-3}$ to allow for short term fluctuations of the $\mathrm{CNnc}$ which trigger the cessation of sampling by exceeding the threshold value while the one minute average $C N n c$ is still well below the set threshold.

Both the sector controlled sampling system and the Aethalometer AE-9 were located in Shore Laboratory 2, connected by sampling lines with diameters of about $8 \mathrm{~mm}$ to inlets at about $8 \mathrm{~m}$ above ground. Distance of Shore Laboratory 2 to the shoreline varied with the tide and ranged from $50 \mathrm{~m}$ to $100 \mathrm{~m}$.

The results from the sector controlled sampling suggest a value of $\sigma_{\text {ATN }}$ for polluted continental aerosol of about $25 \mathrm{~m}^{2} / \mathrm{g}$. For the marine sector samples, the thermal value is much lower $\left(\sigma_{\mathrm{ATN}} 7 \mathrm{~m}^{2} / \mathrm{g}\right)$ which is in agreement with the value obtained by Liousse et al. (1993) for remote sites supposed to be impacted by aged BC particles. However, the thermo-optical BC determination of the samples yielded conflicting results with $\sigma_{\mathrm{ATN}} 35 \mathrm{~m}^{2} / \mathrm{g}$. This discrepancy, which points to an overestimate of $\mathrm{BC}$ by the thermal method or/and underestimate by the thermo-optical procedure, may be explained by different hypotheses. Firstly it is possible that the $\mathrm{BC}$ content determined by the thermal method is higher than the actual $\mathrm{BC}$ content of the aerosol due to charring of OC during the precombustion stage. This might occur significantly for North Atlantic marine aerosol, which during the spring and summer months contains a large amount of biogenic OC and higher molecular organic compounds 
(O'Dowd et al., 2004). The latter may interfere with the optical analysis through their own brown colour. Higher molecular weight organic compounds may also interfere with the charring correction of the thermal method because their refractory nature makes them likely to resist the combustion of $\mathrm{OC}$ at $340^{\circ} \mathrm{C}$. A characterisation of the macromolecular structures in the marine aerosol at Mace Head is required in order to verify this hypothesis. On the other hand the $\mathrm{BC}$ content determined by the thermo-optical method may be underestimated for the following reason: at the onset of the $\mathrm{BC}$ quantification, when the filter sample has regained its original colour through oxidation of absorbing material, the carbon on the sample consists of a mixture of atmospheric $\mathrm{BC}$ and charred organic material. This may lead to an underestimation of $\mathrm{BC}$ because the porous charred material is of lower specific weight compared to atmospheric BC particles (Chylek et al., 2002). It may be possible to improve the thermal and thermo-optical determination of BC at Mace Head by removing the water soluble aerosol fraction prior to BC evaluation. Novakov and Corrigan (1995) have shown that a substantial fraction of organic carbon aerosol can be removed through aqueous extraction.

Thus, it is possible that both the thermal and thermooptical methods do not yield the true $\mathrm{BC}$ contents of the aerosol. Therefore, the Aethalometer measurement results reported in this work are presented as the light attenuation values of the aerosol collected on the Aethalometer filter divided by the length of the sampled air column. This quantity, $\sigma_{\text {att }}\left[\mathrm{Mm}^{-1}\right]$, includes light attenuation due to both particle absorption and multiple particle scattering within the quartz fibre filter matrix. Although the $\mathrm{BC}$ mass attenuation efficiency of $19 \mathrm{~m}^{2} / \mathrm{g}$, specified by the Aethalometer manufacturer, Magee Scientific, may not be the correct value for the aged aerosol of the Mace Head clean sector, it is used in this work when reference is made to $\mathrm{BC}$ mass concentrations.

\section{Statistical considerations}

In the statistical analysis of the presented time series of $\sigma_{\text {att }}$, standard statistical tools are used, which are common in environmental data analysis and well-understood techniques. The confidence intervals and probability values (p-values) computed with these techniques are based on the assumption that the data they describe can be approximated by a normal distribution. Hence, each of the presented data sets is tested to whether or not it fulfils the criterion of normality or whether it can be logarithmically transformed in order to fulfil it.

In a normal distribution the mean of the data is equal to its mode, i.e. the mean of the data describes the value at which the frequency of occurrence of the values is highest. Thus, for a data set which is normally distributed, the mean of that data set describes the value which is most likely to be encountered at any one observation.

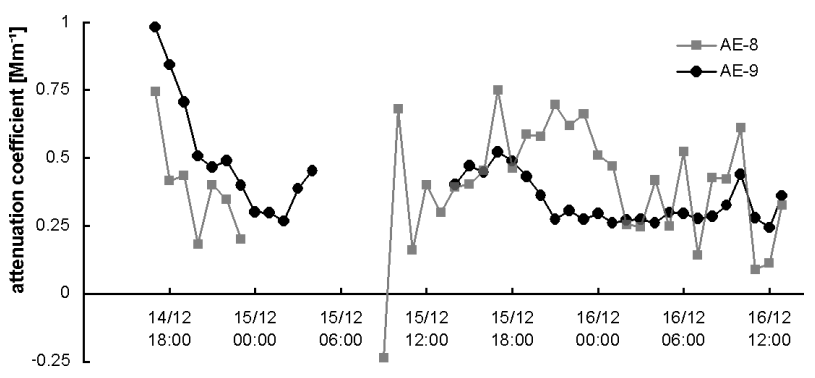

Fig. 4. Aerosol attenuation coefficient as measured by Aethalometer models AE-8 and AE-9 in December 1993.

For a data set where neither its values nor their logarithms are normally distributed, neither its mean nor its geometric mean represents the most likely value at any one observation. Instead, the most likely value is given by the mode of that data set. However, the mode of the data set can vary considerably as a function of the division of the data range into bins, which can be linear or logarithmic. Thus, in a case where a data set is neither normally nor lognormally distributed, there is no single value that adequately characterises the most typical value of that data set. Instead, such a data set is characterised by both its mean and its mode. The time series of the continental sector $\sigma_{\text {att }}$ analysed in Sect. 7 represents such a case where the data distribution departs from both normality and lognormality. Therefore, both mean and mode are presented for the continental sector $\sigma_{\text {att }}$. The same procedure is followed for marine $\sigma_{\text {att }}$ in order to maintain consistency of the presentation.

\section{Aethalometer measurements}

The measurements have been made on a continuous basis with occasional unavoidable breaks. The use of the two different Aethalometer models AE-8 and AE-9 did not affect the continuity of the measurements. Figure 4 shows the hourly averaged attenuation measurements of the two models during the period of colocation of the two instruments. The steadier values of model AE-9 compared to AE-8 in Fig. 4 suggest that model AE-9 has better stability. A paired t-test of the null hypothesis that the data sets from the two Aethalometers have the same mean, yields a p-value of 0.47. A p-value describes the probability of obtaining through random error alone a value of the appropriate test statistic that is at least as large as the one observed, given that the null hypothesis is true. Thus, the obtained p-value suggests a satisfactory degree of agreement between the two instruments.

Up to 1994 the measurements were made for sampling periods between 5 and $60 \mathrm{~min}$. The subsequent measurements were exclusively based on a 5 min sampling period. The analysis presented here is based on $1 \mathrm{~h}$ averages of the data. 


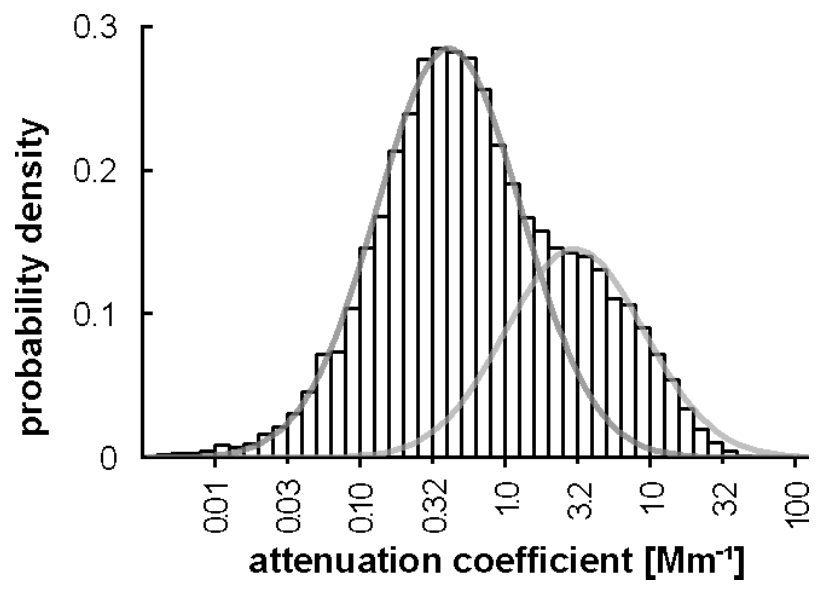

Fig. 5. Distribution of occurrence of hourly averaged aerosol attenuation coefficients for the period 2/1989 to 3/2003. The two lognormal distributions are visually best fitted to the data.

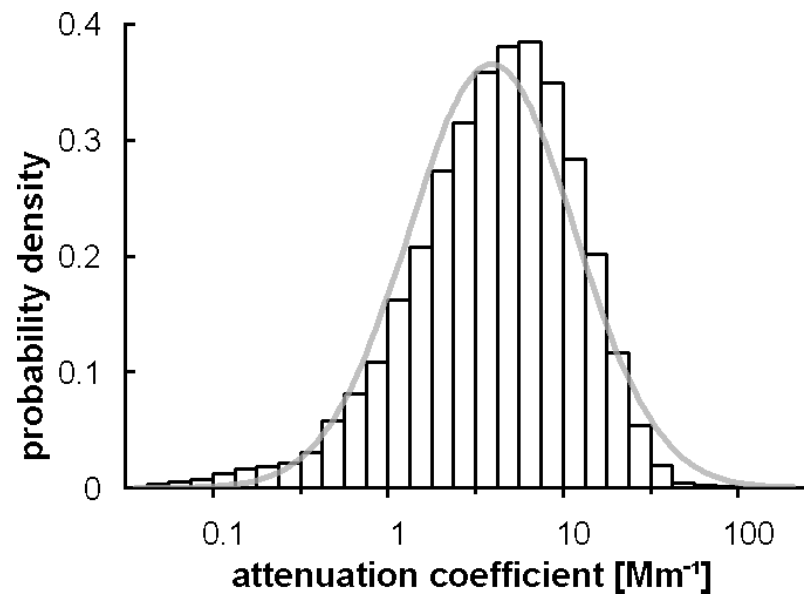

Fig. 6. Probability density function of the frequency of occurrence of the 12738 hourly averaged continental sector attenuation coefficients for the period $18 / 01 / 89$ to $28 / 02 / 03$. The lognormal distribution fitted to the data is shown as a grey line, with a geometric mean $(\mathrm{gm})=3.93 \mathrm{Mm}^{-1}$ and a standard deviation of the logarithms $(s)=1.9$.

The distribution of occurrence of the hourly averaged aerosol light attenuation measurements from February 1989 to March 2003 is shown on a logarithmic scale in Fig. 5. The distribution shows two modes, representing measurements of marine background aerosol and continental aerosol, respectively. These modes emerge when the data is divided into logarithmically sized bins and are therefore referred to in this text as logarithmic modes. The logarithmic mode corresponding to marine sector conditions of $\sigma_{\text {att }} 0.4 \mathrm{Mm}^{-1}$ (equivalent to $C_{M, \mathrm{BC}} 21 \mathrm{ng} / \mathrm{m}^{3}$ ) is within the range of mean concentrations found at other marine sites in Panama, Junker et al. (2004) and in Korea, Kim et al. (2000), see Table 1.

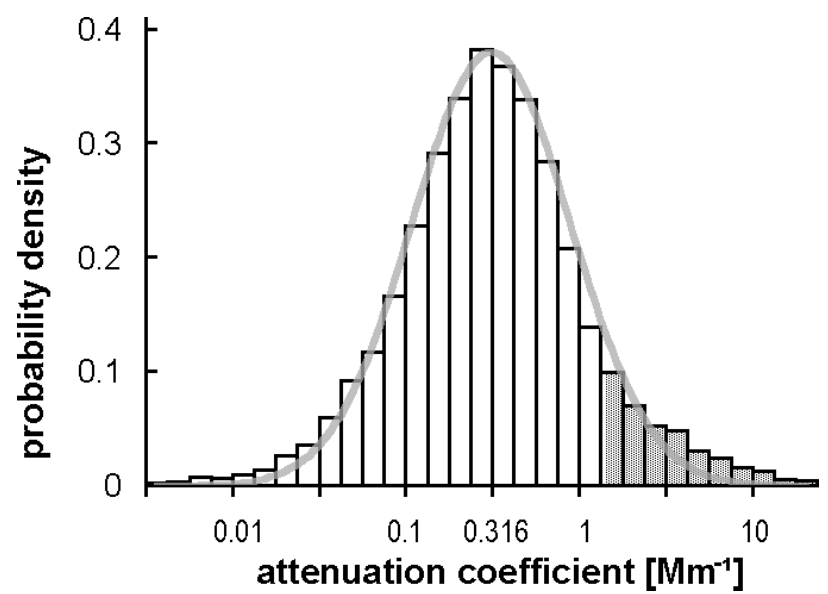

Fig. 7. Probability density function of the frequency of occurrence of the hourly averaged marine sector attenuation coefficients for the period $2 / 1989$ to $3 / 2003$, with a lognormal distribution centred at the mean of the data. The shaded part of the columns represents the attenuation coefficients $>1.425 \mathrm{Mm}^{-1}$, which are excluded from the time series analysis of marine air.

The logarithmic mode corresponding to continental sector conditions of $\sigma_{\text {att }} 3.4 \mathrm{Mm}^{-1}$ (equivalent to $C_{M, \mathrm{BC}} 179 \mathrm{ng} / \mathrm{m}^{3}$ ) is comparable to $C_{M, \mathrm{BC}}$ reported for remote continental sites by Junker et al. (2004) and by Echalar et al. (1998).

Figure 6 shows the distribution of the continental sector $\left(45^{\circ}<W D<135^{\circ}\right)$ hourly attenuation coefficients on a logarithmic scale. The geometric mean is $3.9 \mathrm{Mm}^{-1}$, corresponding to $C_{M, \mathrm{BC}} 207 \mathrm{ng} / \mathrm{m}^{3}$. However, the logarithmic mode of this data set is at $6.5 \mathrm{Mm}^{-1}$ corresponding to $C_{M, \mathrm{BC}} 342 \mathrm{ng} / \mathrm{m}^{3}$. The mismatch between the data and a lognormal distribution is evident from the fitted lognormal distribution, superimposed in Fig. 6. It follows that the geometric mean is not the most likely occurring value of $\sigma_{\text {att(continental sector) }}$. The reason lies in the skewness of the distribution towards higher values. The distribution of the nonlogarithmically converted hourly averages (figure not shown) is also skewed but towards lower values. This suggests that the continental sector data is neither normally nor lognormally distributed. Thus, both the arithmetic and the geometric means and modes for continental and marine air masses are listed in Table 2.

The distribution of the marine sector hourly attenuation coefficients on a logarithmic scale is shown in Fig. 7. The figure shows a close match between the distribution of the measured data and a lognormal distribution centred at the geometric mean of the data of $0.310 \mathrm{Mm}^{-1}$. The difference between the geometric mode and the geometric mean of the data of $1.2 \%$ is not significant with respect to the standard error of the geometric mean of $1.2 \%$. This suggests that the hourly marine sector attenuation coefficient is adequately described by its geometric mean. It is consistent with Pinnick et al. (1993) who have shown that the probability density, 
Table 1. Values for BC mass concentrations at marine and coastal sites.

\begin{tabular}{|c|c|c|c|c|}
\hline Region & Period of measurement & $\begin{array}{l}\text { Measurement/Analytical } \\
\text { method }\end{array}$ & $\begin{array}{l}\text { BC mass concentration } \\
{\left[\mu \mathrm{g} / \mathrm{m}^{3}\right]}\end{array}$ & References \\
\hline Canal Zone, Panama & Jul 1976-Mar 1979 & transmission $\left(\sigma_{\mathrm{ATN}}=19 \mathrm{~m}^{2} / \mathrm{g}\right)$ & 0.059 & Junker et al. (2004) \\
\hline Crete & Jul-Aug 2001 & thermal method, Cachier (1989) & 1.09 & Sciare et al. (2003) \\
\hline Kosan, Cheju island, Korea & Feb 1996-Apr 1999 & selective thermal oxidation method 1 & $0.09-0.43$ & Kim et al. (2000) \\
\hline Amsterdam Island, Indian Ocean & Jan 1991- Dec 1993 & thermal method, Cachier (1989) & 0.008 & Cachier (1996) \\
\hline Halley Station, Antarctica & Sep 1992-Jun 1995 & Aethalometer $\left(\sigma_{\mathrm{ATN}}=19 \mathrm{~m}^{2} / \mathrm{g}\right)$ & 0.001 & Wolff and Cachier (1998) \\
\hline Southern Nova Scotia, Canada & Aug and Sep 1993 & Thermo-optical $^{2}$ & 0.11 & Chylek et al. (1996) \\
\hline Mauna Loa, Hawaii & Jan-Dec 1992 & Aethalometer $\left(\sigma_{\mathrm{ATN}}=19 \mathrm{~m}^{2} / \mathrm{g}\right)$ & 0.0058 & Bodhaine (1995) \\
\hline $\begin{array}{l}\text { North East Atlantic, Mace Head, Ireland } \\
\text { (marine sector air only) }\end{array}$ & Feb 1989-Jun 1996 & Aethalometer $\left(\sigma_{\mathrm{ATN}}=19 \mathrm{~m}^{2} / \mathrm{g}\right)$ & $0.010-0.020$ & Cooke et al. (1997) \\
\hline North East Atlantic & Oct and Nov 1989 & Aethalometer $\left(\sigma_{\mathrm{ATN}}=19 \mathrm{~m}^{2} / \mathrm{g}\right)$ & 0.015 & O’Dowd et al. (1993) \\
\hline North East Atlantic & Feb 1989-Mar 2003 & Aethalometer $\left(\sigma_{\mathrm{ATN}}=19 \mathrm{~m}^{2} / \mathrm{g}\right)$ & 0.016 & This work \\
\hline
\end{tabular}

${ }^{1} \mathrm{OC}$ oxidised for $3 \mathrm{~min}$ at $525^{\circ} \mathrm{C}$ in the presence of $\mathrm{MnO}_{2}$, oxidation of $\mathrm{BC}$ at $850^{\circ} \mathrm{C}$ (Fung, 1990).

${ }^{2} \mathrm{BC}$ is determined from the change in transmittance of the filter sample upon slow heating to $700^{\circ} \mathrm{C}$ and oxidation to $\mathrm{CO}_{2}$; calibration with laboratory BC aerosol (Malissa, 1976).

Table 2. Geometric and arithmetic means and modes for marine and continental sector hourly averaged aerosol attenuation coefficients at Mace Head for the period 2/1989 to 3/2003. The uncertainty intervals of the means correspond to \pm 2 standard errors. The uncertainty intervals for the modes correspond to the observed range of modes obtained with data bin sizes varying from $\ln \left\{\sigma_{\text {att }}\left[\mathrm{Mm}^{-1}\right]\right\}=0.23$ to 0.45 .

\begin{tabular}{lcc}
\hline & $\begin{array}{c}\text { attenuation } \\
\text { coefficient } \\
{\left[\mathrm{Mm}^{-1}\right]}\end{array}$ & $\begin{array}{c}\text { BC mass } \\
\text { concentration* } \\
{\left[\mathrm{ng} / \mathrm{m}^{3}\right]}\end{array}$ \\
\hline marine sector & & \\
\hline geometric mean & $0.310 \pm 0.004$ & $16.3 \pm 0.2$ \\
geometric mode & $0.303 \pm 0.005$ & $15.9 \pm 0.3$ \\
arithmetic mean & $0.709 \pm 0.016$ & $37.3 \pm 0.8$ \\
arithmetic mode & $0.133 \pm 0.020$ & $7.0 \pm 1.1$ \\
\hline continental sector & & \\
\hline $\begin{array}{l}\text { geometric mean } \\
\text { geometric mode } \\
\text { arithmetic mean } \\
\text { arithmetic mode }\end{array}$ & $3.93 \pm 0.08$ & $207 \pm 4$ \\
\hline
\end{tabular}

* Based on BC mass attenuation efficiency of $19 \mathrm{~m}^{2} / \mathrm{g}$.

i.e. the normalised frequency of occurrence of weekly and biweekly averages of continental background aerosol attenuation coefficients can be expected to follow a lognormal distribution. Figure 7 also shows the portion of the marine sector data which is excluded from the time series analysis because it does not represent marine sector conditions, using the marine sector filter criterion of $\sigma_{\text {att }}<1.425 \mathrm{Mm}^{-1}$.

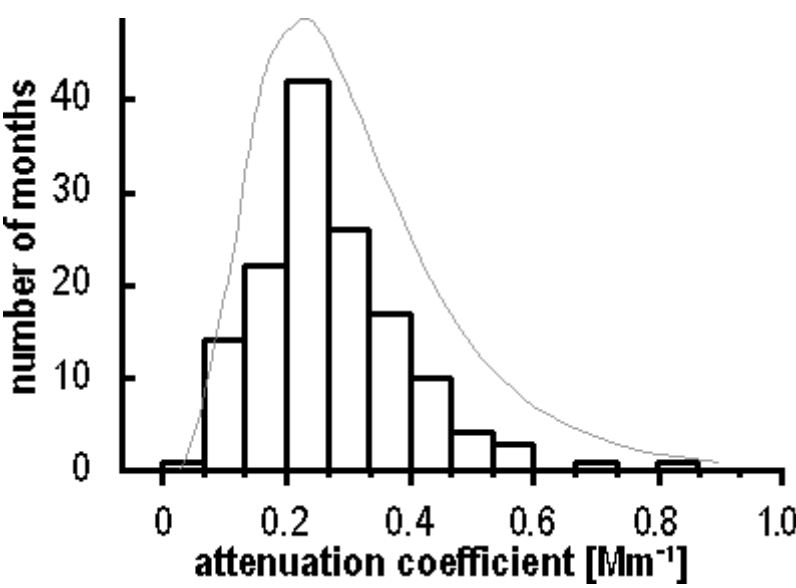

Fig. 8. Distribution of occurrence of the monthly geometric means of the marine sector aerosol attenuation coefficients used for constructing the time series for the period from $2 / 1989$ to $3 / 2003$. A lognormal distribution with a geometric mean $g m$ of $0.253 \mathrm{Mm}^{-1}$ and a standard deviation of the logarithms $s=0.47$ is also shown (gmand $s$ are calculated from the logarithms of the monthly geometric mean $\left.\sigma_{\text {att }}\right)$.

\section{Time series of monthly aerosol attenuation coeffi- cients}

The frequency of occurrence of the monthly geometric mean marine $\sigma_{\text {att }}$ is also found to follow approximately a lognormal distribution as shown in Fig. 8 as was found for the hourly values of marine $\sigma_{\text {att }}$. No statistically significant departure from lognormality is found by the Kolmogorov-Smirnov test for normality. The confidence intervals and p-values of significance tests used in the time series analysis are derived from the logarithms of the monthly geometric mean values 


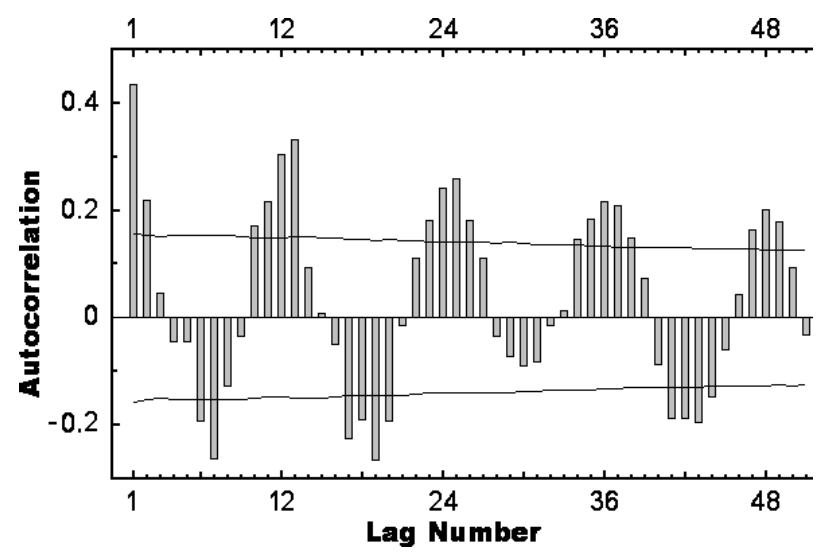

Fig. 9. Autocorrelation of the time series $2 / 1989$ to $3 / 2003$ of the logarithms of the monthly geometric mean marine sector $\sigma_{\text {att }}$.

of $\sigma_{\text {att }}$.

The autocorrelation analysis of the time series of monthly marine sector $\sigma_{\text {att }}$, shown in Fig. 9, reveals significant first order autocorrelation. Thus, multiple autoregression is used for the quantitative analysis of the trends and seasonal components of the time series instead of ordinary multiple regression. Autoregressive analysis is a combination of autocorrelation and regression analysis. The first order autocorrelation of the time series is calculated and subtracted from the series. A linear (multiple) regression is performed on the resulting new series.

Besides first order autocorrelation, the time series shows significant autocorrelation at all lags which are multiples of 12, up to lag 48 (Fig. 9). Following Bowerman and O'Connell (1993), this is an indication of 12-month seasonality of the time series. Hence, besides the time variable $t, 12$ seasonal parameters are included in the linear autoregressive model. The model which is found to describe the time series most accurately is of the form:

$\ln \left\{\sigma_{\mathrm{att}}\right\}_{t}=\alpha+\beta t+\sum_{i=1}^{12} S_{i} m_{i, t}+\varepsilon_{t}$

where $t$ is the time in months and $\alpha\left[\ln \left\{\mathrm{Mm}^{-1}\right\}\right]$ and $\beta$ $\left[\ln \left\{\mathrm{Mm}^{-1}\right\}\right]$ denote the intercept and the slope (trend of the time series). $m_{i}$, with $i=1,2, \ldots, 12$, is the variable indicating the presence of each month, which takes values of one or zero. For example, the variable $m_{2}$ takes a value of 1 if $t$ denotes the month of February, and 0 when $t$ represents another month. $S_{i}\left[\ln \left\{\mathrm{Mm}^{-1}\right\}\right]$ is the seasonal index for month $i$ with $i=1,2, \ldots, 12$. It represents the effect of the month of the year on the magnitude of the model output. The error term $\varepsilon_{t}$ represents a first order autoregressive process. In ordinary linear regression analysis $\varepsilon_{t}$ would represent a white noise process.

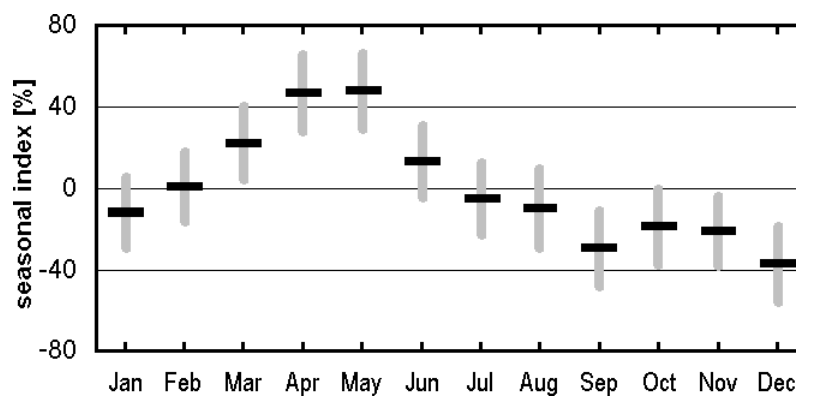

Fig. 10. Seasonal indices of the autoregressive model as percentage of $\sigma_{\text {att }}$ given by the autoregressive trend line for the marine sector monthly geometric mean $\sigma_{\text {att }}$ at Mace Head for the period 2/1989$3 / 2003$. The error bars represent $95 \%$ confidence intervals.

The intercept, slope and the seasonal indices $S_{i}$ of the model are determined by multiple autoregression analysis, where the logarithms of the monthly aerosol attenuation coefficients are regressed on $t$ and on $m_{i}$ with $(i=1,2, \ldots, 11)$. The twelfth seasonal index is found by

$S_{12}=\sum_{i+1}^{11} S_{i}$

The 12 seasonal indices of the fitted autoregressive model (expressed as a percentage of $\sigma_{\text {att }}$ at each point of the autoregressive trendline) are shown in Fig. 10. The figure shows May and April as the months with the highest marine sector aerosol attenuation. A minor secondary maximum of the seasonal cycle is found for the October and November months.

The effect of regional rainfall on the seasonal cycle was calculated using daily rainfall measurements at a local coastal meteorological observing site at Roundstone about $6 \mathrm{~km}$ north of Mace Head. The geometric mean marine sector attenuation coefficients for days with precipitation are $35 \%$ lower than for days without precipitation, even though the correlation of the daily marine sector attenuation coefficients with daily rainfall amount is poor $\left(r^{2}=0.02\right)$.

The effect of rainfall on the marine sector monthly and annual geometric mean attenuation coefficient is illustrated in Fig. 11. The figure shows that the monthly and the annual mean precipitation plotted on an inverted scale are approximately tracking the monthly and annual geometric mean $\sigma_{\text {att }}$.

Figure $11 \mathrm{~b}$ shows that the peak in the annual attenuation coefficient at Mace Head around the year 1996 coincides with a minimum in the annual rainfall rate and that many (but not all) of the other maxima in $\sigma_{\text {att }}$ coincide with minima of annual rainfall rate and vice-versa. However, there is no long-term trend in annual rainfall rate unlike the observed trend of $\sigma_{\text {att }}$ as shown later.

The dependence of the seasonal cycle of marine aerosol attenuation coefficients on local wind direction is suggested by Fig. 12, which shows the yearly cycle of the occurrence of marine sector and continental sector conditions in the Mace 


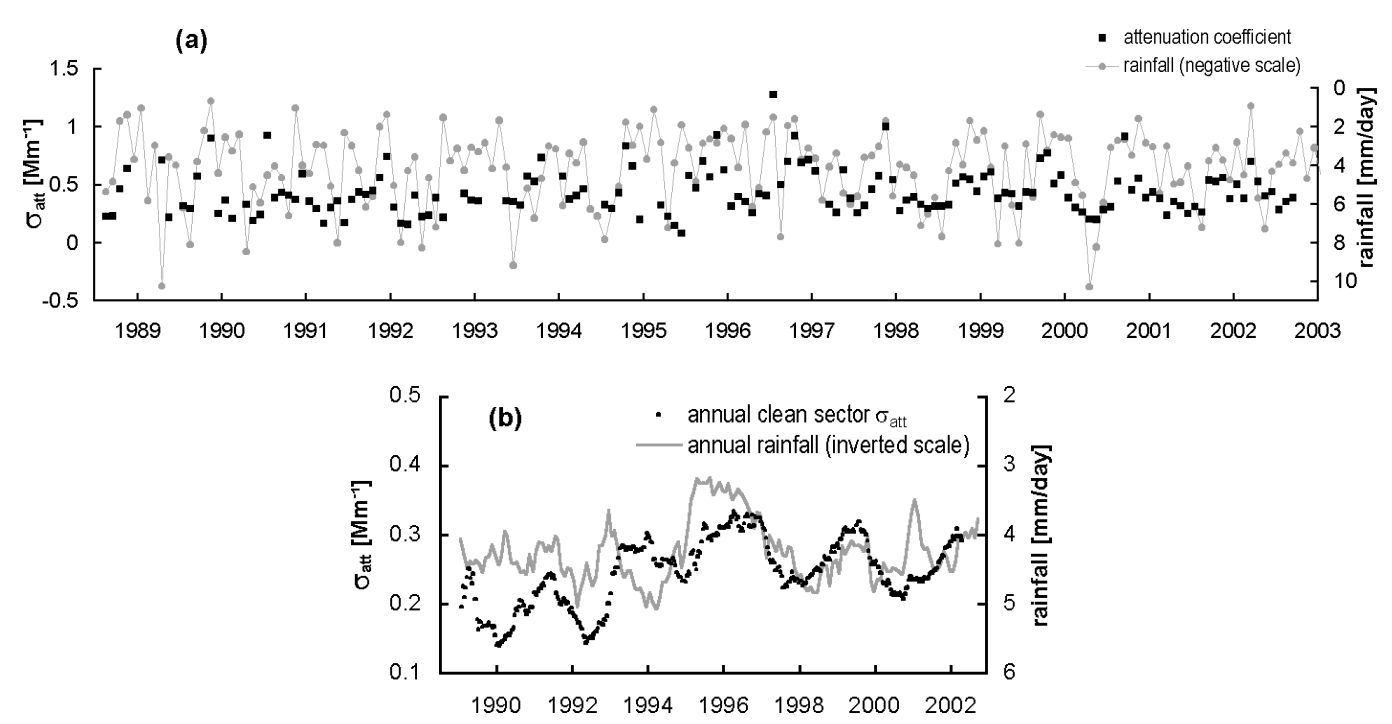

Fig. 11. (a) Monthly geometric mean marine sector $\sigma_{\text {att }}$ at Mace Head and monthly averages of the daily rainfall amount, and b) annual geometric mean marine sector $\sigma_{\text {att }}$ at Mace Head and annual averages of the daily rainfall amount.

Head area. It is evident from this figure that there is a minimum of the marine sector conditions and a maximum of the continental sector conditions in May. An increased occurrence of easterly airflows during May is also suggested by the seasonal cycle of Lamb airflow indices for the British Isles. The Lamb indices represent subjective classifications of each day by experienced meteorologists (using two to three weather charts) into airflow categories established by Lamb (1972). In fact, the indices show May as the only month of the year for which easterly airflows dominate over westerlies. It is possible that an increased occurrence of easterly airflows causes an increase of the marine sector BC concentrations at Mace Head, due to mixing of continental air with marine air over the Atlantic. Another contributor to elevated aerosol attenuation coefficients in spring may consist of the breakdown of the Arctic vortex, which releases polluted air accumulated in the Arctic Haze during Winter (Amery et al., 1992). This phenomenon usually takes place from late April to late May.

During the period 1989 to 1997 the seasonal maximum of $\sigma_{\text {att }}$ occurs in May, whereas April is the month with highest $\sigma_{\text {att }}$ for the period 1998 to 2003. Cooke et al. (1999) have shown that for the period 1990 to 1997, the seasonal peak of measured marine sector BC concentrations in May at Mace Head is well replicated by their model calculations.

Figures 13 and 14 show the time series of monthly aerosol attenuation coefficients for the continental and the marine sector together with the autoregressive trendlines. Two separate trend calculations were performed for the periods 19891997 and 1997-2003 because the data shows a discontinuity in its long-term trend in 1997 for both continental and marine sector. For both sectors, the yearly attenuation co-

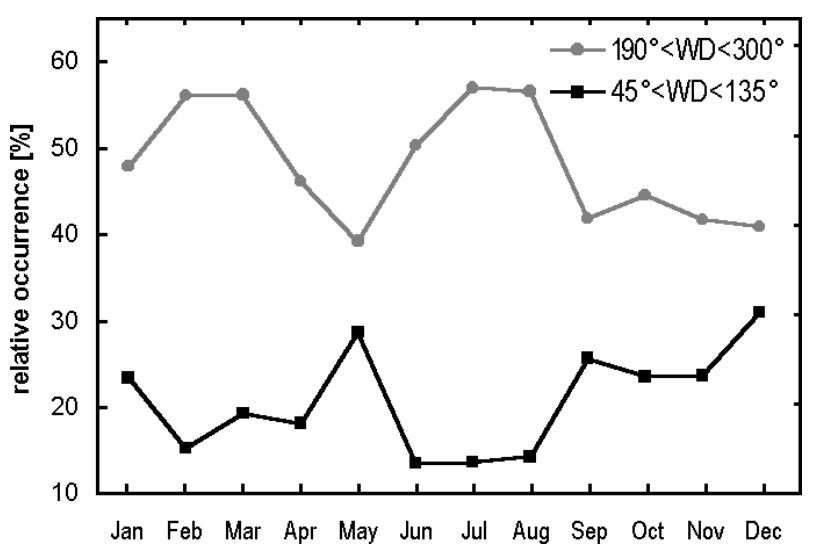

Fig. 12. Relative occurrences [\%] of marine sector $\left(190^{\circ} i r c<W D<300^{\circ}\right)$ and continental sector $\left(45^{\circ}<W D<135^{\circ}\right)$ conditions for the period $2 / 1989$ to $3 / 2003$.

efficient measured at Mace Head nearly doubles during the period 1989-1997, whereas no significant trend is present during the period 1997-2003. The geometric means for each year and the trend values are given in Table 3.

The method of multiple autoregressive analysis for the determination of trend and seasonal influences was chosen because of its transparency and repeatability, which arises from the fact that its key element, linear regression, is a familiar tool for trend analysis. This is in contrast to Sharma et al. (2004) who use an unspecified geometric time variation model to analyse a 13 year time series of Aethalometer measurements in the Canadian Arctic. The authors estimate the parameters of their model by maximising a (unspecified) loglikelihood function of the model. 


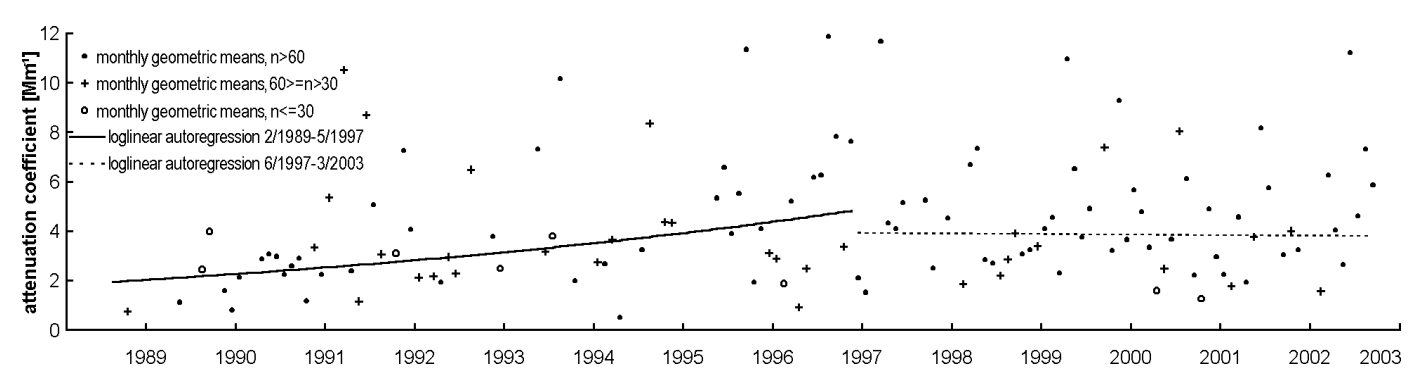

Fig. 13. Monthly geometric means of the continental sector aerosol attenuation coefficients with trend lines determined by autoregression analysis. The number of hourly values is represented by $n$. Values denoted by a cross are monthly geometric means calculated from less than 60 hourly values. Open circles denote means calculated from less than 30 hourly values. The markers on the abscissa denote the middle of each year (30 June).

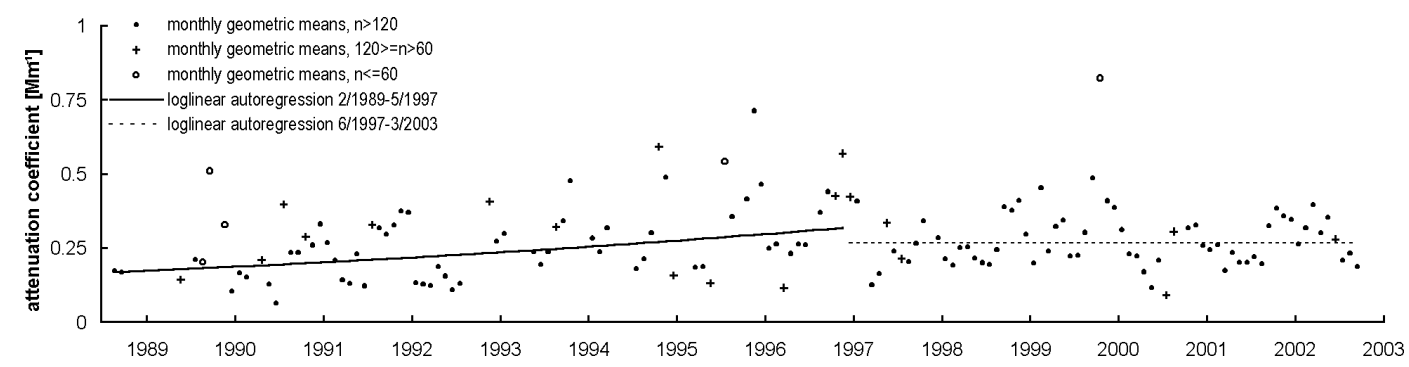

Fig. 14. Monthly geometric means of the marine sector aerosol attenuation coefficients with trend lines determined by autoregression analysis. The number of hourly values is represented by n. Values denoted by a cross are geometric means calculated from less than 120 hourly values. Open circles denote means calculated from less than 60 hourly values. The markers on the abscissa denote the middle of each year (30 June).

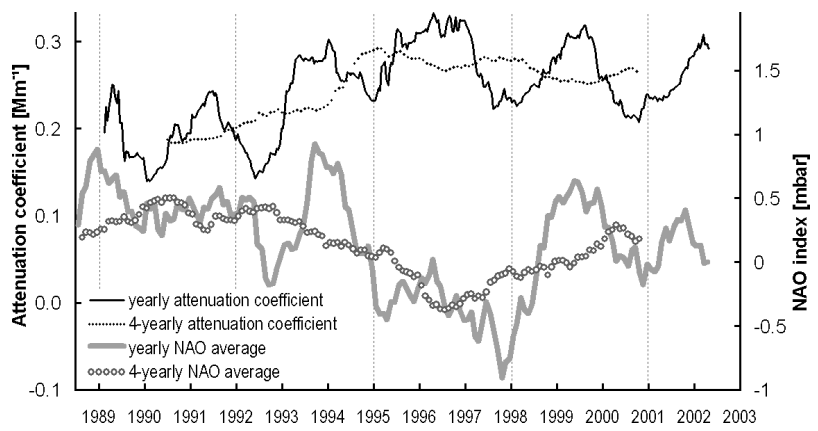

Fig. 15. Yearly and 4-yearly running geometric means of marine sector $\sigma_{\text {att }}$ at Mace Head, and averages of monthly NAO indices. An approximate three-year cycle of $\sigma_{\text {att }}$ is indicated by dashed vertical lines.

The long-term trends evident in the attenuation coefficient at Mace Head is in contrast to the trend found by Sharma et al. (2004) at the Canadian Arctic for the same period. They find a decrease of 55 to $60 \%$ for the period 1989 to 2000 and a small increase from 2000 to 2002, evident from their Fig. 3a. Sharma et al. (2004) find that the observed trends can be explained by a variation of the emission source strength only for air originating from the former USSR. The trends ob- served at Mace Head do not correspond to any of the changes in emission source strengths given by Sharma et al. (2004) for the former USSR, Western Europe or North America.

However, the increase of the unsectored monthly attenuation coefficients at Mace Head between 1989 and 1997 by a factor of three from $0.43 \mathrm{Mm}^{-1}$ to $1.21 \mathrm{Mm}^{-1}$ (Table 3 ) is in agreement with the results calculated from the global atmospheric tracer transport model TM3 (Guelle et al., 2001) by Liousse and Cachier (manuscript in preparation), who predict unsectored BC concentrations at Mace Head to increase by the same factor with values increasing from $35 \mathrm{ng} / \mathrm{m}^{3}$ for the year 1989 to $100 \mathrm{ng} / \mathrm{m}^{3}$ for 1997 .

The North Atlantic Oscillation (NAO) is defined as the changes in atmospheric pressure difference between the Azores high pressure systems and the Icelandic low pressure systems. Figure 15 shows yearly averages of $\sigma_{\text {att }}$ and of the NAO indices calculated by the National Oceanic and Atmospheric Administration of the USA, NOAA, available for anonymous download at ftp://ftpprd.ncep.noaa.gov/pub/cpc/ wd52dg/data/indices/tele_index.nh. The positive trend of $\sigma_{\text {att }}$ during the years 1989 to 1997 is accompanied by a negative trend of the NAO indices, and the small negative trend of $\sigma_{\text {att }}$ following the year 1997 is accompanied by a rise in the NAO indices. This pattern becomes even more prominent when the apparent approximate 3-year cyclicity present in 
Table 3. Yearly geometric means and long-term trends of the marine sector, the continental sector and unsectored aerosol attenuation coefficients, and equivalent BC aerosol mass concentrations at Mace Head for the period 18 January 1989 to 31 March 2003 . For the yearly geometric means the errors are given as \pm 2 times the average of the upper and the lower geometric standard error.

\begin{tabular}{|c|c|c|c|c|c|c|c|c|c|}
\hline \multirow[b]{3}{*}{ year } & \multicolumn{3}{|c|}{ marine sector } & \multicolumn{3}{|c|}{ continental sector } & \multicolumn{3}{|c|}{ unsectored } \\
\hline & \multicolumn{2}{|c|}{ geometric annual mean ${ }^{1}$} & \multirow{2}{*}{$\begin{array}{c}\text { auto-regression } \\
\text { slope }^{2} \\
{[\% / \text { annum }]}\end{array}$} & \multicolumn{2}{|c|}{ geometric annual mean ${ }^{1}$} & \multirow{2}{*}{$\begin{array}{c}\text { auto-regression } \\
\text { slope }^{2} \\
{[\% / \text { annum }]}\end{array}$} & \multicolumn{2}{|c|}{ geometric annual mean ${ }^{1}$} & \multirow{2}{*}{$\begin{array}{c}\text { auto-regression } \\
\text { slope }^{2} \\
{[\% / \text { annum }]}\end{array}$} \\
\hline & $\begin{array}{c}\sigma_{\mathrm{att}} \\
{\left[\mathrm{Mm}^{-1}\right]}\end{array}$ & $\begin{array}{c}C_{M, \mathrm{BC}} \\
{\left[\mathrm{ng} / \mathrm{m}^{3}\right]}\end{array}$ & & $\begin{array}{c}\sigma_{\mathrm{att}} \\
{\left[\mathrm{Mm}^{-1}\right]}\end{array}$ & $\begin{array}{c}C_{M, \mathrm{BC}} \\
{\left[\mathrm{ng} / \mathrm{m}^{3}\right]}\end{array}$ & & $\begin{array}{c}\sigma_{\text {att }} \\
{\left[\mathrm{Mm}^{-1}\right]}\end{array}$ & $\begin{array}{c}C_{M, \mathrm{BC}} \\
{\left[\mathrm{ng} / \mathrm{m}^{3}\right]}\end{array}$ & \\
\hline 1989 & $0.192 \pm 0.013$ & $10.1 \pm 0.7$ & & $2.74 \pm 0.61$ & $144 \pm 32$ & & $0.43 \pm 0.03$ & $22.7 \pm 1.5$ & \\
\hline 1990 & $0.137 \pm 0.008$ & $7.2 \pm 0.4$ & & $2.23 \pm 0.18$ & $117 \pm 9$ & & $0.36 \pm 0.02$ & $18.9 \pm 0.9$ & \\
\hline 1991 & $0.213 \pm 0.008$ & $11.2 \pm 0.4$ & & $2.82 \pm 0.22$ & $148 \pm 12$ & & $0.53 \pm 0.02$ & $28.0 \pm 1.1$ & \\
\hline 1992 & $0.194 \pm 0.006$ & $10.2 \pm 0.3$ & & $3.82 \pm 0.27$ & $201 \pm 14$ & & $0.49 \pm 0.02$ & $26.0 \pm 0.9$ & \\
\hline 1993 & $0.202 \pm 0.011$ & $10.6 \pm 0.6$ & $7.7 \pm 3.6$ & $4.71 \pm 0.54$ & $248 \pm 28$ & $10.9 \pm 7.3$ & $0.47 \pm 0.03$ & $25.0 \pm 1.5$ & $13.3 \pm 6.6$ \\
\hline 1994 & $0.301 \pm 0.012$ & $15.8 \pm 0.6$ & & $2.94 \pm 0.26$ & $155 \pm 14$ & & $0.74 \pm 0.03$ & $39.0 \pm 1.6$ & \\
\hline 1995 & $0.232 \pm 0.009$ & $12.2 \pm 0.5$ & & $5.04 \pm 0.38$ & $265 \pm 20$ & & $0.71 \pm 0.03$ & $37.3 \pm 1.5$ & \\
\hline 1996 & $0.310 \pm 0.011$ & $16.3 \pm 0.6$ & & $4.85 \pm 0.28$ & $255 \pm 15$ & & $0.90 \pm 0.03$ & $47.3 \pm 1.6$ & \\
\hline 1997 & $0.318 \pm 0.013$ & $16.7 \pm 0.7$ & & $5.24 \pm 0.26$ & $276 \pm 14$ & & $1.21 \pm 0.04$ & $63.8 \pm 2.3$ & \\
\hline 1998 & $0.232 \pm 0.008$ & $12.2 \pm 0.4$ & & $4.37 \pm 0.31$ & $230 \pm 16$ & & $0.64 \pm 0.02$ & $33.9 \pm 1.2$ & \\
\hline 1999 & $0.284 \pm 0.008$ & $14.9 \pm 0.4$ & & $4.36 \pm 0.23$ & $229 \pm 12$ & & $0.70 \pm 0.02$ & $36.9 \pm 1.2$ & \\
\hline 2000 & $0.257 \pm 0.008$ & $13.5 \pm 0.4$ & $-0.1 \pm 6.0$ & $4.47 \pm 0.25$ & $235 \pm 13$ & $-0.6 \pm 9.8$ & $0.70 \pm 0.02$ & $37.0 \pm 1.2$ & $-1.0 \pm 9.6$ \\
\hline 2001 & $0.235 \pm 0.008$ & $12.4 \pm 0.4$ & & $3.40 \pm 0.22$ & $179 \pm 12$ & & $0.58 \pm 0.02$ & $30.4 \pm 1.0$ & \\
\hline 2002 & $0.291 \pm 0.007$ & $15.3 \pm 0.4$ & & $3.92 \pm 0.26$ & $207 \pm 13$ & & $0.68 \pm 0.02$ & $36.0 \pm 1.2$ & \\
\hline
\end{tabular}

1 Yearly geometric mean of hourly values.

${ }^{2}$ Calculated from the time series of monthly geometric means of hourly values.

both $\sigma_{\text {att }}$ and NAO indices is removed by calculating 4-year moving averages (also shown in Fig. 15). A negative correlation between NAO index and aerosol attenuation coefficient is expected since stronger cyclones north of Mace Head and stronger anticyclones over the Azores in the south will contribute to an increase in flow of clean westerly air masses to Mace Head accompanied by decreasing attenuation coefficient $\sigma_{\text {att }}$. Thus, it is likely that changes in weather systems and circulation patterns over the North Atlantic have an important effect on observed marine sector $\sigma_{\text {att }}$ at Mace Head.

The observed increase of $\sigma_{\text {att }}$ of continental sector air up to 1997 is possibly related to increasing BC emissions over Ireland, calculated from the fuel consumption data base of the statistical division of the United Nations (UNSTAT, 2002). This data shows a sharp increase since 1989 and a stagnation in 1997 of BC emissions over Ireland, whereas the same pattern can only be observed in a minor way for Western Europe.

\section{Conclusions}

The work contains ample material on light absorbing aerosol - measured continuously over quite a long period of time (14 years) at Mace Head, which is representative of the North Atlantic region.

Statistical analysis of the data set yields useful results such as: (a) Hourly aerosol absorption data follow a log-normal distribution

(b) Valuable information on the arithmetic mean (0.709 $\left.\mathrm{Mm}^{-1}\right)$, geometric mean $\left(0.31 \mathrm{Mm}^{-1}\right)$ and on the modes for marine sector hourly averaged aerosol attenuation coefficients; and values for the arithmetic mean $\left(6.36 \mathrm{Mm}^{-1}\right)$, geometric mean $\left(3.93 \mathrm{Mm}^{-1}\right)$ and for the modes for the continental sector hourly averaged values.

A rigorous time series analysis, using multiple autoregression, was carried out of monthly aerosol attenuation coefficients $\sigma_{\text {att }}$ at Mace Head, and it has shown evidence of a significant upward trend in $\sigma_{\text {att }}$ measurements for the marine sector $(+7.7 \% /$ annum $)$, the continental sector $(+10.9 \% /$ annum) and for the un-sectored (+13.3\%/annum) air masses from 1989 up to 1997 , but no significant trend thereafter.

The months with highest marine sector $\sigma_{\text {att }}$ are found to be April and May. This monthly variation of the aerosol attenuation coefficient observed at Mace Head appears to be influenced by local wind direction and rainfall amount. Likewise, changes in North Atlantic weather patterns as indicated by the NAO indices appear to be a major factor driving the observed trend changes in marine aerosol attenuation. The comparison with global emissions calculated by Sharma et al. (2004) for the Northern hemisphere suggests that variations in source strength are not major factors for influencing the observed trends of $\sigma_{\text {att }}$ at Mace Head for the period 1989 
to 2003. However, modelling results of Liousse and Cachier (manuscript in preparation) predict a sharp rise in BC (unsectored) concentrations at Mace Head between 1989 and 1997, which could be due to the coincidental occurrence of changes in meteorological conditions (influencing primarily the clean sector) and an abrupt increase of Irish emissions during the same period (influencing primarily the continental sector).

Acknowledgements. For the period from 1989 to 2000, technical support of the Aethalometer measurements was provided by T. G. Spain.

Acknowledgements are given for the assistance of K. Oikonomou at the Laboratory for the Science of Climate and Environment LSCE for the thermal and thermo-optical analysis of the filter samples.

The CORE project (Climate-biOspheRe intEractions) is acknowledged for financial assistance under European Union (EU) Contract No. EVR1-CT1999-40009.

Edited by: R. Hitzenberger

\section{References}

Ackerman, A. S., Toon, O. B., Stevens, D. E., Heymsfield, A. J., Ramanathan, V., and Welton, E. J.: Reduction of tropical cloudiness by soot, Science, 288, 1042-1047, 2000.

Amery, C. A., Haberle, R. M., and Ackerman, T. P.: A onedimensional modelling study of carbonaceous haze effects on the springtime Arctic environment, J. Geophys. Res.-Atmos., 97, 20 599-20 613, 1992.

Andreae, M. O., Andreae, T. W., Ferek, R. J., and Raemdonck, H.: Long-range transport of soot carbon in the marine atmosphere, Sci. Total Environ., 36, 73-80, 1984.

Bowerman, B. L. and O'Connell, R. T.: Forecasting and Time Series: An Applied Approach, 3rd ed., Duxbury Press, Boston, MA, pp. 572, 1993.

Bodhaine, B. A.: Aerosol Absorption Measurements at Barrow, Mauna Loa and the South Pole, J. Geophys. Res.-Atmos., 100, 8967-8975, 1995.

Cachier, H., Liousse, C., Pertuisot, M. H., Gaudichet, A., Echalar, F., and Lacaux, J. P.: African fire particulate emissions and atmospheric influence, in Biomass Burning and Global Change, edited by: Levine, J. S., 1, 428-440, 1996.

Cachier, H., Bremond, M.-P., and Buat-Ménard, P.: Determination of atmospheric soot carbon with a simple thermal method, Tellus-B, 41, 3, 379-390, 1989.

Chow, J., Watson, J. G., Pritchett, L. C., Pierson, W. R., Frazier, C. A., and Purcell, R. G.: The DRI thermal/optical reflectance carbon analysis system: Description, evaluation and applications in U.S. air quality studies, Atmos. Environ., 27A, 1185-1201, 1993.

Chylek, P., Jennings, S. G., and Pinnick, R.: Soot, in: Encyclopaedia of Atmospheric Science, edited by: Holton, J., Curry, J. A., and Pyle, J. A., Elsevier Press, 2093-2099, 2002.

Chylek, P., Banic, C., Damiano, P., Isaac, G., Johnson, B., Leaitch, R., Liu, P., Ngo, D., Said, F., and Winter, B.: Black Carbon: Atmospheric Concentrations and Cloud Water Content Measurements over Southern Nova Scotia, J. Geophys. Res.-Atmos., 101, 29 105-29 110, 1996.
Cooke, W. F., Liousse, C., Cachier, H., and Feichter, J.: Construction of a $1^{\circ} \times 1^{\circ}$ fossil fuel emission data set for carbonaceous aerosol and implementation and radiative impact in the ECHAM4 model, J. Geophys. Res.-Atmos., 104, 18, 22 137$22162,1999$.

Cooke, W. F., Jennings, S. G., and Spain, T. G.: Black Carbon Measurements at Mace Head: 1989-1996, J. Geophys. Res.-Atmos., 102, 25 339-25 346, 1997.

Draxler, R. R. and Hess, G. D.: Description of the HYSPLIT 4 Modelling System, NOAA Technical Memorandum ERL ARL224, available for anonymous ftp download at http://www.arl. noaa.gov/hysplit.html, 1998.

Echalar, F., Artaxo, P., Martins, J. V., Yamasoe, M., and Gerab, F.: Long-term monitoring of atmospheric aerosols in the Amazon Basin: Source identification and apportionment, J. Geophys. Res.-Atmos., 103, 31 849-31 864, 1998.

Fung, K.: Particulate carbon speciation by $\mathrm{MnO} 2$ oxidation, Aerosol Science \& Technology, 12, 1, 122-127, 1990.

Guelle, W., Schulz, M., Balkanski, Y., and Dentener F.: Influence of the source formulation on modelling the atmospheric global distribution of sea salt aerosol, J. Geophys. Res.-Atmos, 106, 27 509-27 524, 2001.

Gundel, L. A., Dod, R. L., Rosen, H., and Novakov, T: The relationship between optical attenuation and black carbon concentration for ambient and source particles, Sci. Total Environ., 36, 197202, 1984.

Hansen, J. and Nazarenko, L.: Soot climate forcing via snow and ice albedos, Proc. Natl. Acad. Sci. USA, 101, 423-428, 2004.

Hansen, J., Sato, M., and Ruedy, R.: Radiative forcing and climate response, J. Geophys. Res.-Atmos., 102, 6831-6864, 1997.

Hansen, A. D. A., Rosen, H., and Novakov, T.: The aethalometer, an instrument for the real time measurement of optical absorption by aerosol particles, Sci. Total Environ., 36, 191-196, 1984.

Hansen, A. D. A., Rosen H., and Novakov, T.: Real time measurement of the absorption coefficient of aerosol particles, Appl. Opt., 21, 3060-3062, 1982.

Haywood, J. M. and Ramaswamy, V.: Global sensitivity studies of the direct radiative forcing due to anthropogenic sulfate and black carbon aerosols, J. Geophys. Res.-Atmos., 103, 60436058, 1998.

Houghton, J. T., Ding, Y., Griggs, D. J., Noguer, M., van der Linden, P. J., Dai, X., Maskell, K., and Johnson, C. A.: Third assessment report of the intergovernmental panel on climate change, Cambridge University Press, Cambridge, UK, 2001.

Jacobson, M. Z.: Strong radiative heating due to the mixing state of black carbon in atmospheric aerosols, Nature, 409, 695-697, 2001.

Jennings, S. G., Francis, J., Spain, T. G., Donaghy, T., Geever, M., and McGovern, F. M.: Microphysical and physico-chemical characterization of atmospheric marine and continental aerosol at Mace Head, Atmos. Environ. 31, 2795-2808, 1997.

Jennings, S. G. and Pinnick, R. G.: Relationships between visible extinction, absorption and mass concentration of carbonaceous smokes, Atmos. Environ., 14, 1123-1129, 1980.

Johnson, B. T, Shine, K. P., and Forster, P. M.: The semi-direct aerosol effect: impact of absorbing aerosols on marine stratocumulus, Q. J. R. Meteorol. Soc., 130, 1407-1422, 2004.

Junker, C.: Aerosol light absorption in a marine environment and its relation to black carbon aerosol mass concentration, $\mathrm{Ph} . \mathrm{D}$. thesis, 
National University of Ireland, Galway, 2004.

Junker, C., Sheahan, J. N., Jennings, S. G., O’Brien, P., Hinds, B. D., Martinez-Twary, E., Hansen, A. D. A., White, C., Garvey, D. M., and Pinnick, R. G.: Measurement and analysis of aerosol and black carbon in the southwestern United States and Panama and their dependence on air mass origin, J. Geophys. Res.-Atmos, 109, D13201, doi:10.1029/2003JD004066, 2004.

Kim, Y. P, Lee, J. H., Kim, J. Y, Fung, K., Carmichael, G. R., Song, C. H., Kang, C. H., Kim, H.-K., Lee, C. B., Moon, K.-C., and Shim, S.-G.: Carbonaceous species in fine particles at the background sites in Korea between 1994 and 1999, Atmos. Environ., 34, 5053-5060, 2000.

Lamb, H. H.: British Isles weather types and a register of daily sequence of circulation patterns, 1861-1971, Geophysical Memoir 116, HMSO, London, pp. 85, 1972.

Lavanchy, V. M. H., Gäggeler, H. W, Nyeki, S., and Baltensperger, U.: Elemental Carbon (EC) and Black Carbon (BC) Measurements with a Thermal Method and an Aethalometer at the HighAlpine Research Station Jungfraujoch, Atmos. Environ., 33, 2759-2769, 1999.

Liousse, C., Cachier, H., and Jennings, S. G.: Optical and thermal measurements of black carbon aerosol content in different environments: Variation of the specific Attenuation cross-section, sigma $(\sigma)$, Atmos. Environ., 1203-1211, 1993.

Macias, E. S., Zwicker, J. O., Ouimett, J. R., Hering, S. V., Friedlander, S. K., Cahill, T. A., Kuhlmey, G. A., and Richards, L. W.: Regional haze case studies in the south-western US - I. Aerosol chemical composition, Atmos. Environ., 15, 1971-1986, 1981.

Malissa, H., Puxbaum, H., and Pell, E.: Zur Simultanen Relativkonduktometrischen Kohlenstoff und Schwefelbestimmung in Stauben, Z. Anal. Chem., 282, 109-113, 1976.

Novakov, T. and Corrigan, E.: Thermal Characterization of Biomass Smoke Particles, Mikrochim. Acta, 119, 157-166, 1995.

O’Dowd, C. D., Facchini, M. C., Cavalli, F., Ceburnis, D., Mircea, M., Decesari, S., Fuzzi, S., Yoon, Y. J., and Putaud, J.-P.: Biogenically driven organic contribution to marine aerosol, Nature, 431, 676-680, 2004.

O'Dowd, C. D. and Smith, M. H.: Physio-chemical properties of aerosol over the North East Atlantic: Evidence for wind speed related sub-micron sea-salt aerosol production, J. Geophys. Res.Atmos., 98, 1137-1149, 1993.
Petzold, A., Kopp, C., and Niessner, R.: The dependence of the specific attenuation cross-section on black carbon mass fraction and particle size, Atmos. Environ., 31, 661-672, 1997.

Pinnick, R. G., Fernandez, G., Martinez-Andazola, E., Hinds, B. D., Hansen, A. D. A., and Fuller, K.: Aerosol in the arid southwestern United-States - measurements of mass loading, volatility, size distribution, absorption characteristics, black carbon content, and vertical structure to $7 \mathrm{~km}$ above sea-level, J. Geophys. Res.-Atmos., 98, 2651-2666, 1993.

Sciare, J., Cachier, H., Oikonomou, K., Ausset, P., Sarda-Estève, R., Mihalopoulos, N., and Andreae, M. O.: Characterization of carbonaceous aerosols during the MINOS campaign in Crete, JulyAugust 2001: a multi-analytical approach, Atmos. Chem. Phys., 3, 1743-1757, 2003.

Sharma, S., Lavoué, D., Cachier, H., Barrie, L. A., and Gong, S. L.: Long-term trends of the black carbon concentrations in the Canadian Arctic, J. Geophys. Res.-Atmos., 109, D15203, doi:10.1029/2003JD004331, 2004.

Sharma, S., Brook, J. R., Cachier, H., Chow, J., Gaudenzi, A., and Lu, G.: Light absorption and thermal measurements of black carbon in different regions of Canada, J. Geophys. Res.-Atmos., 107, D4771 ,doi:10.1029/2001JD004331, 2002.

Simpson, J. E.: Sea breeze and local winds, Cambridge University Press, Cambridge, 1994.

Seinfeld, J. H. and Pandis, S. N.: Atmospheric Chemistry and Physics, 430 pp., 1117 pp., 1153 pp., John Wiley \& Sons, Inc., New York, USA, 1998.

Stohl, A.: Computation, accuracy and applications of trajectories A review and bibliography, Atmos. Environ., 32, 947-966, 1998.

Turco, R. P.: Earth under Siege, 339 pp., Oxford University Press, Oxford, UK, 1997.

UNSTAT: The United Nations energy statistics database (2002), Tech. rep., Stat. Div., New York, 2002.

Wolff, E. W. and Cachier, H.: Concentrations and seasonal cycle of black carbon in aerosol at a coastal Antarctic station, J. Geophys. Res.-Atmos., 103, 11 033-11 041, 1998.

Wolff, G. T., Groblicki, P. J., Cadle, S. H., and Countess, R. J.: Particulate carbon at various locations in the United States, in: Particulate carbon: atmospheric life cycle, edited by: Wolff, G. T. and Klimisch, R. L., Plenum Press, New York, 297-315, 1982. 